Amerikanisch-jüdische Lebensentwürfe 
Frank Scheerer

\section{Amerikanisch-jüdische Lebensentwürfe}

Saul Bellow / Bernard Malamud /

Cynthia Ozick / Chaim Potok / Philip Roth

Verlag J.B.Metzler Stuttgart · Weimar 
Bibliografische Information Der Deutschen Bibliothek Die Deutsche Bibliothek verzeichnet diese Publikation in der Deutschen Nationalbibliografie; detaillierte bibliografische Daten sind im Internet über <http://dnb.ddb.de> abrufbar

ISBN 978-3-476-45317-4

ISBN 978-3-476-02932-4 (eBook) DOI 10.1007/978-3-476-02932-4

Dieses Werk einschließlich aller seiner Teile ist urheberrechtlich geschützt. Jede Verwertung außerhalb der engen Grenzen des Urheberrechtsgesetzes ist ohne Zustimmung des Verlages unzulässig und strafbar. Das gilt insbesondere für Vervielfältigungen, Übersetzungen, Mikroverfilmungen und die Einspeicherung und Verarbeitung in elektronischen Systemen.

M \& P Schriftenreihe für Wissenschaft und Forschung

(C) 2004 Springer-Verlag GmbH Deutschland

Ursprünglich erschienen bei J.B.Metzlersche Verlagsbuchhundlung und Carl Ernst Poeschel Verlag GmbH in Stuttgart 2004 


\section{Inhaltsverzeichnis}

Vorwort

Erstes Kapitel: Einleitung

1. Einleitung: Dual identity

Zweites Kapitel: Ozick/Roth - Literaturentwürfe

2.1. Amerikanisch-jüdische Literatur

Versuch einer Standortbeschreibung

2.2. America:Toward Yavneh - Cynthia Ozicks Verständnis von jüdischer Literatur im amerikanischen Kontext

2.3. Reading Myself and Others: Philip Roths Kritik an der Ästhetisierung und moralischen Erhöhung jüdischer Protagonisten in der amerikanisch-jüdischen Literatur

Drittes Kapitel: Bellows Mr Sammler's Planet

3.1 Judentum: Ethnizität, Holocaust survival und Konservativismus in Saul Bellows Mr Sammler's Planet

3.2. Ein tribalistischer Lebensentwurf: die Familie als identitätsstiftendes Merkmal

3.3. Ethnische Identität: Sammler als Holocaust survivor

3.4. Fremdheitsempfinden im US-Kontext

3.5. Konservativismus: Werteverbundenheit - gespeist durch jüdische Ethik - als Kritik an der (Post-)Moderne

3.6. Sammler: A worldly Tsadek?

\section{Viertes Kapitel: Malamuds The Assitant}

4.1. Jüdische Ethik als literarisches Moment in Bernard Malamuds The Assistant

4.2. Ethnizität in The Assistant

4.3. Jüdische Ethik als literarisches Moment

4.4. Schlemieh1/Schlimassel: Prototypen jüdischer Erzähltradition 47

4.5. Bobers Negation der Wertmaßstäbe des American Dream 49

4.6. Universalismus, ein jüdisches Grundprinzip? 
Fünftes Kapitel: Potoks The Chosen

5.1. Tradition und Religion im Spannungsfeld der Moderne in Chaim Potoks The Chosen 54

5.2. Talmud-Toragelehrsamkeit - Quelle jüdischer Religiosität $\quad 56$

5.3. Orthodoxie versus Chassidismus 60

5.4. Zionismus in The Chosen- Reaktion auf die Shoa und Affirmation jüdischer Identität in den USA 64

5.5. Amerika - eine marginale Größe in The Chosen? 66

Sechstes Kapitel: Lebensentwürfe

6. Konklusion 71

$\begin{array}{ll}\text { Epilog } & 75\end{array}$

$\begin{array}{ll}\text { Literaturverzeichnis } & 78\end{array}$ 


\section{Vorwort}

„Dem freien Geiste“ ist das Auditorium Maximum der Universität Heidelberg gewidmet. In Heidelberg nahmen meine Studien ihren Ausgang, um in Berlin an der Freien Universität und schließlich, dank des DAAD-Stipendiums und einer Scholarship der Brandeis University, in den USA fortgesetzt zu werden. Danksagen möchte ich meinen akademischen Lehrern aus Heidelberg an der Hochschule für Jüdische Studien, insbesondere Professor Dr. Evyatal Friesel, der mich durch seine historischen Seminare neugierig auf amerikanisch-jüdische Themen machte. Ebenso danke ich Professor Dr. Daniel Krochmalnik, der mein kritisches Denken schulte. Für die Formung schulde ich Professor Dr. Yehuda Radday, seligen Angedenkens, Respekt. Den Judaisten Professor Dr. Michael Brocke und Professor Dr. Peter Schäfer bin ich für meine Berliner Zeit verpflichtet, sowie den Hochschullehrem des John F. Kennedy-Institutes für die Unterstützung meiner Studien in den USA, Professor Dr. Knud Krakau und Professor Dr. Heinz Ickstadt, Letzerem auch für die Gewährung der Freiheit bei der Wahl und Ausarbeitung meines Themas. Undenkbar wäre die vorliegende Arbeit ohne die Lehrenden an der Brandeis University am Near Eastern and Judaic Studies Program (NEJS), insbesondere Professorin Dr. Sylvia BarakFishman, die mich in jeglicher Weise förderte und mir die Gelegenheit gab, die Schriftsteller Philip Roth, Saul Bellow und Rebecca Goldstein persönlich zu erleben, ebenso Professor Dr. Jonathan Sarna, der mich in den historischen Kontext amerikanisch-jüdischer Lebenswelten einführte. Mein academic advisor Professor Dr. Antony Polonsky beriet mich, wie in den USA üblich, nicht nur in Studienangelegenheiten.

Dank sei meiner Frau Stephanie und ihrer Familie, ebenso meiner Familie. Erinnert sei an meinen Urgroßvater Julius Krajewsky, der auf dem Weg von Kattowice in die Neue Welt in Hamburg einen faustischen Bund schloss und bis zu seinem Tode als Schriftsetzer für das Hamburger Fremdenblatt arbeitete.

Die Abfassung des Textes, kritischer Apparat, Zitate und Bibliographie ist den in der Amerikanistik üblichen Konventionen angepasst. Die deutsche Transliteration hebräischer Ausdrücke entspricht dem im Jüdischen Lexikon festgelegten Standard.

Hamburg/Berlin im Frühjahr 2004

Frank Scheerer 